\title{
Segmenting Adolescents Around Social Influences on Their Eating Behavior: Findings From Italy
}

\author{
Sabina De Rosis' ${ }^{\circledR}$, Francesca Pennucci', \\ and Chiara Seghieri'
}

\begin{abstract}
Adolescence is a fundamental period in everyone's life. Teenagers have for the first time the possibility to take on responsibility about their choices in many domains, building their own "lifestyle." Among these domains, food is one of the most important considering the implications for their future health. Deep knowledge of teenagers' behaviors and of factors affecting their choices can support tailored health policy and social marketing interventions for this population. The purpose of this article is to prospectively segment teenagers around food socialization factors as influencing factors of food preferences, attitudes, and behaviors of adolescents. A cluster analysis (CA) was performed on a sample of 4,749 respondents aged 15 and 18 years coming from Tuscany (Italy). Considering food wellbeing and consumer socialization frameworks, the CA used three food socialization variables related to influences and source of information/advices at intrapersonal, interpersonal, and broader societal levels. Five distinct groups were identified and described, showing deep differences in the adolescents' food behaviors corresponding to different socialization patterns. Adolescents who reported broader food socialization at all investigated levels present better lifestyle habits. Social marketers, policy makers, and health professionals can work on specific influencing food socialization factors for tailoring marketing interventions and increasing their positive impact on adolescents' food behaviors.
\end{abstract}

\section{Keywords}

food choice, adolescence, health promotion, social influence, cluster analysis

Social marketing interventions should be designed with consumers' habits in mind (Verplanken \& Wood, 2006) and based on a deep knowledge and segmentation of the target population (Andreasen, 2002; Dibb, 2017; Kotler \& Lee, 2008; Snyder et al., 2004). Segmentation is a very effective way for finding well-defined homogenous groups in larger populations (Woodside, Nielson, Walters, \& Muller, 1998), in order to effectively design and target behavioral change interventions, more effectively measure outcomes, address specific cognitive and behavioral patterns, and change behaviors of

\footnotetext{
' Laboratorio Management and Sanità, Institute of Management - EMbeDS Department, Scuola Superiore Sant'Anna, Pisa, Italy
} 
specific homogenous groups (Andreasen, 2002; Dietrich, Rundle-Thiele, Leo, \& Connor, 2015; Gordon, 2013; Lefebvre, 2011, 2013; Luecking et al., 2017; Newton, Newton, Turk, \& Ewing, 2013).

In a complex and evolving environment, as the health-care delivery is, segmentation offers relevant insights into health-care consumers' behaviors and attitudes (Swenson, Bastian, \& Nembhard, 2018). Health-care systems have increasingly oriented their strategies toward a patient-centered approach, which sees individuals as active participants in managing their health (Richards, Coulter, \& Wicks, 2015). This appears particularly relevant in health promotion and prevention initiatives, considering the crucial role that individuals play in preventing illnesses, by adopting healthy conducts. In this respect, both positive and negative behaviors developed during adolescence are taken forward into adult life (Patton et al., 2016; World Health Organization [WHO], 2014), also leading to eating disorders, obesity, and, more in general, chronic non-communicable diseases (NCDs; Catalano et al., 2012; Whitaker, Wright, Pepe, Seidel, \& Dietz, 1997). Considering that more than two thirds of premature adult deaths are linked to NCDs, reflecting behaviors started or reinforced during adolescence (Catalano et al., 2012; Resnick, Catalano, Sawyer, Viner, \& Patton, 2012), promoting a correct and healthy lifestyle to adolescents might produce benefits and value at individual and societal levels (Catalano et al., 2012). In NCDs-predominant countries, as many as one adolescent in every three is obese (Dick, \& Ferguson, 2015). Globally, fewer than one in four adolescents meet recommendations for physical activity (i.e., $60 \mathrm{~min}$ per day) and the great majority (80-90\%) does not follow the guidelines on nutrition-related behaviors (i.e., fruit and/or vegetables daily consumption; Dick \& Ferguson, 2015). Prevention of obesity can be effectively addressed in an early period of life, by using social marketing as a key strategy.

Social marketing strategies include segmentation (Andreasen, 2002), which facilitates in avoiding one-fits-all interventions (Dietrich, Rundle-Thiele, \& Kubacki, 2017). Segmentation has found a limited use in social marketing interventions (Kubacki et al., 2017), also in interventions aimed at improving adolescents' lifestyle-related behaviors (Dietrich, Rundle-Thiele, Schuster, \& Connor, 2016; Duane, Domegan, McHugh, \& Devaney, 2016; Hoek \& Jones, 2011; Lefebvre, 2011; Lefebvre \& Flora, 1988; Parkinson, Schuster, \& Russell-Bennett, 2016; Seiders \& Petty, 2004). In order to effectively target adolescents by sending healthy messages and using changing-behaviors strategies, it is essential to have a deep knowledge of specific groups and lifestyle behaviors of the target audience, but also of whatever and how other relevant factors influence these behaviors.

Teenagers develop attitudes and behaviors via a social learning process (Moschis \& Churchill, 1978). Socialization agents (e.g., parents, peers, and media) significantly influence consumer skills and decision-making process of teenagers (Moschis, 1985; Moschis \& Churchill, 1978; Moschis \& Moore, 2016; Churchill \& Moschis, 1979; Wang, Yu, \& Wei, 2012). A recent study explored social-related antecedents of technology readiness of teenagers, demonstrating their effect on adolescents' behaviors (Mishra, Maheswarappa, \& Colby, 2018). Also digital media, web 2.0, and social contagion and imitation processes among peers, which characterize adolescence (Aral, \& Walker, 2011), should be considered among influencing factors. The effectiveness of change behavior interventions toward teenagers also depends on understanding and involvement of networks, community, and environment/ context (Duane et al., 2016; Hastings, McDermott, \& Anderson, 2000; Luca, Hibbert, \& McDonald, 2016; Parkinson et al., 2016; Spotswood \& Tapp, 2013). Segmentation in social marketing mainly uses traditional demographic variables, such as age and ethnicity, despite a wider range of variables can be used as base for segmentation, including behavioral and psychographic variables (Dietrich, 2017). The literature recommends the use of behavioral and psychographic variables for more sophisticated and meaningful segmentation (Dietrich et al., 2017). Thus, segmentation should also consider variables from consumer socialization domains to match individual-micro and social-meso/macro levels (Brennan, Previte, \& Fry, 2016) and avoid the one-fits-all approach.

To the best of the authors' knowledge, several studies describe adolescents' dietary patterns; a few studies segmented teenagers on the basis of their eating behaviors, but without including socialization 
factors that may affect their food-related decision-making process (Burke et al., 1997; Campain et al., 2003; Contento, Michela, \& Goldberg, 1988; Newby \& Turker, 2004). Long before the digital revolution and the new millennium distinctive phenomena, a cluster analysis (CA) conducted on 355 adolescents included peers and family influence on food choice as socialization factors (Contento et al., 1988). This study demonstrated that adolescents are not a homogeneous group with respect to these influencing factors. More recent studies identified segments of adolescents based on their online shopping behaviors (Hill, Beatty, \& Walsh, 2013) or technology readiness (Mishra et al., 2018). A recent review on health-care market segmentation identified 12 papers (Swenson et al., 2018). In two of these latter, adults were clustered around different lifestyle behaviors (Kolodinsky \& Reynolds, 2009; Moss, Kirby, \& Donodeo, 2009); other two clustered college students: one around health-related behaviors (Berg et al., 2010) and one specifically around substance use behaviors (Suragh, Berg, \& Nehl, 2013). Evidence to inform policy-making and define adolescent-centered social marketing interventions to promote healthy habits still appears not adequate, compared with available data for other age groups (Dick \& Ferguson, 2015).

Given these premises, the purpose of this work is to prospectively segment teenagers around food socialization factors as influencing factors of their food preferences, attitudes, and behaviors. This study aims at providing novel evidence to inform policy makers, health-care managers, and social marketers in order to effectively target lifestyle behavior changing interventions toward adolescents, by considering how external source of influences and information related to different socialization agents can affect teenagers' food choices. Teenagers were clustered around three food socialization factors, according with Block and colleagues' food-well-being (FWB) framework of (2011). The study uses data from a very large survey to late adolescents, ${ }^{1}$ conducted within the beFood project (Pennucci, De Rosis, Murante, \& Nuti, 2019).

\section{The Study Setting}

The study was performed in the Italian region of Tuscany. Italy is a "strong-family" country, where family represents one of the most important socialization agents. Thus, both individuals' food behaviors (Counihan, 2004; Giannotta, Ortega, \& Stattin, 2013) and effectiveness of social marketing and health promotion programs (Coffano, 2010) are affected by the family networks. In Italy, public efforts in social marketing programs toward adolescents are significant, with a high recourse to school-based interventions (Coffano, 2010). Several school-based and/or community-based national programs have been devoted to educate and increase awareness of young people, in order to improve their lifestyle behaviors (i.e., Frutta nelle scuole - "Fruit at school" and "Forchetta and scarpetta"- "Fork and scarpetta" where scarpetta means both shoe and bread-dipping; Lazzeri et al., 2013; Panunzio et al., 2010; http://www.fruttanellescuole.gov.it; http://www.educazionedigitale.it/prodotto/for chetta-e-scarpetta/). Recently, Guadagnare salute negli adolescenti ("Gaining health") has been one of the most important health prevention and promotion programs. It has been developed also in Tuscany (Guadagnare salute in Toscana, DGR n.800/2008) with the multi-sector and integrated strategy Toscana da ragazzi (DGR n.496/2014; https://www.minoritoscana.it/?q=node/555), which included actions on nutrition and physical activity (Coffano, 2010). Despite these valuable efforts, evidence-based interventions are still scarce in the country; also segmentation is not cited into published papers and gray literature about these interventions, thus resulting addressed to the average adolescent (Coffano, 2010).

The region of Tuscany can be considered an interesting context. It presents both above-cited characteristics and some peculiarities too. Tuscan food is considered nutritious and healthy, derived from the traditional Mediterranean diet (Vermeulen et al., 2016). It has a strong identity, being recognized as iconic in Italy as well as in other countries (Stone, Soulard, Migacz, \& Wolf, 2018). Nonetheless, it was found that not all the Tuscan adolescents currently adopt healthy and 
"Mediterranean" choices in respect to food (Berti et al., 2018; Santomauro et al., 2014). Considering that regional and local actions have contributed to the reduction in schoolchildren obesity and overweight in Tuscany (Lazzeri et al., 2015), public programs for improving teenagers' lifestyle behaviors are still needed.

Segmenting adolescents' food behavioral patterns in a context of strong parental and family relationships and with a strong food culture represents a challenge and an interesting setting of both analysis and provision of implications for future interventions.

\section{The Framework}

In this study, the authors consider eating behaviors in adolescence as influenced by several factors at different levels, following the consume socialization theory (Churchill \& Moschis, 1979; Moschis, 1985; Moschis \& Churchill, 1978; Moschis \& Moore, 2016; Wang et al., 2012) and considering the system/ecological perspective of social marketing (Luca et al., 2016). Four levels of influence have been considered under two main domains: individual and societal. The individual domain presents three levels: intrapersonal (i.e., psychosocial, biological), social environment or interpersonal (i.e., family and peers), and physical environment or community settings (i.e., schools, health-care system, food stores). The macro-system or societal level mainly refers to mass media, marketing and advertising, and sociocultural norms. This model was integrated within the domain of food socialization from the FWB framework (Block et al., 2011), as represented in Figure 1.

The "food socialization" is defined as "the process consumers use to learn about food, its role, and FWB in a person's cultural realm" (Block et al., 2011, p. 7). The peers and family influence represents a significant dimension of the food socialization. Despite a progressively increasing autonomy in choosing food (Niemeier, Raynor, Lloyd-Richardson, Rogers, \& Wing, 2006; Patton et al., 2016), teenagers' decisions are still affected by family values, habits, and socioeconomic condition (Block et al., 2011; Patton et al., 2016; Reicks et al., 2015; Videon \& Manning, 2003). During the adolescence, the sensitivity to the reputation is particularly influential on decision-making and great importance is given to peers' perception (Brown, 2004; Reicks et al., 2015; Somerville, 2013; Steinberg \& Monahan, 2007; Viner et al., 2012). However, research is still controversial on this field, demonstrating both a negative (Cwik et al., 2017) and a positive peer influence (protective system; Jaccard, Blanton, \& Dodge, 2005) on teenagers' behaviors.

Internet, digital, and social media represent a great potential source of food information and knowledge increase (Patton et al., 2016) but can also expose adolescents to viral fake information and food commercial advertising. In both cases, the media can influence food-related decisions (Jordan, Kramer-Golinkoff, \& Strasburger, 2008; Snyder, Milici, Slater, Sun, \& Strizhakova, 2006) and, thus, constitute a broader level of food socialization (Block et al., 2011).

The school represents another important source of influence on adolescents' behaviors, health, and well-being (Viner et al., 2012), but evidence on its influence is still controversial. Health-care system, family doctors in particular, can also play a role in influencing lifestyle-related behaviors, but family doctors generally do not address these topics deeply enough (Parkinson et al., 2016). In an ecological perspective (Blum, Bastos, Kabiru, \& Le, 2012), food-related decisions can also be affected by cultural and social norms about food consumption, as well as by food availability and policies regulating access to healthy and unhealthy food (Block et al., 2011; Parkinson et al., 2016; Patrick \& Nicklas, 2005; Steinberg, 2008).

\section{Method}

The present study is based on data collected in 2017 on a convenience sample of 4,749 adolescents coming from 10 provinces of Tuscany (Italy). The survey was administered under the beFood project 


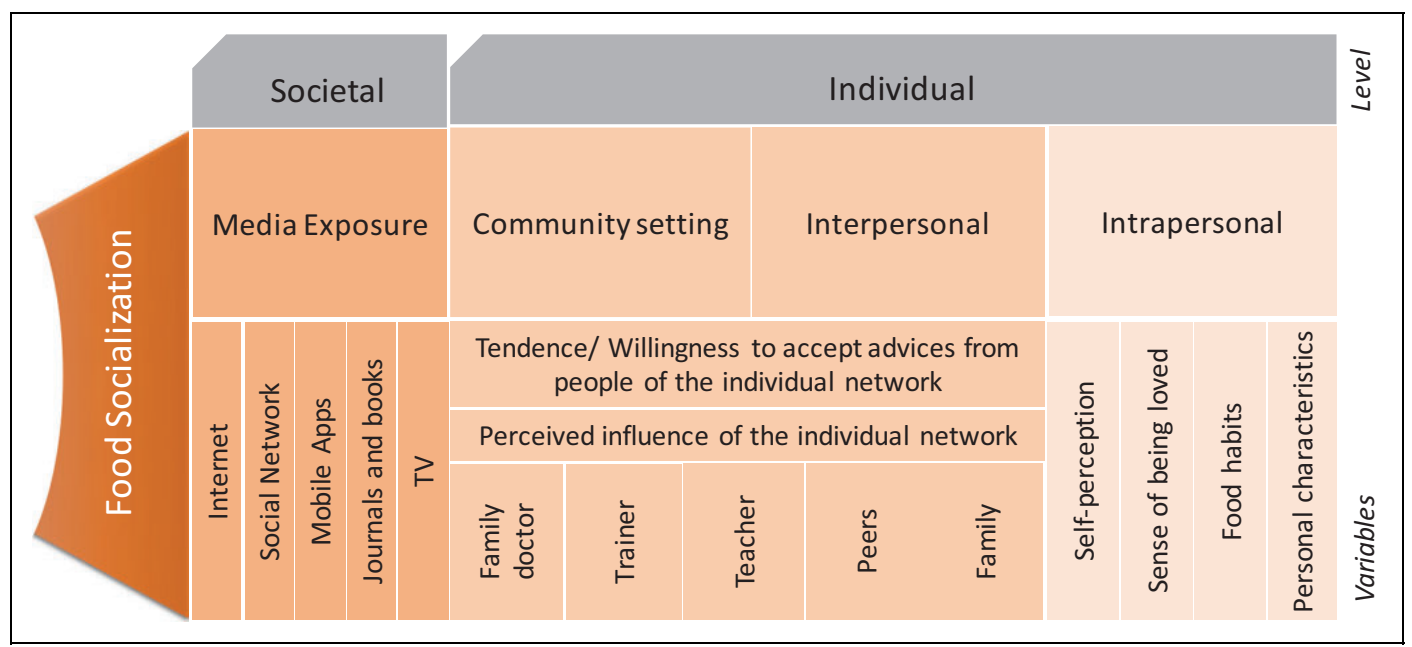

Figure I. Theoretical framework.

through a webAPP, and respondents filled up the questionnaire using either smartphones or computers (Pennucci, De Rosis, \& Nuti, 2018).

\section{The Questionnaire}

Referring to international and national literature (Cramer, 2016; Edit - ARS Toscana, 2015; Paek, Reber, \& Lariscy, 2011; Rose, Poynter, Anderson, Noar, \& Conigliaro, 2013), the authors developed a questionnaire to investigate adolescents' lifestyle behaviors. The questionnaire was divided into three sections and comprised 65 closed-ended questions (33 were Likert-type scale questions) and 11 openended ones.

The first section investigated daily habits looking at frequency levels of food consumption (e.g., weekly consumption of fruit and vegetables). Moreover, family and social norms, such as respondents' habits when eating (e.g., at table, with family, or outside home), were investigated.

The second section investigated adolescents' preferences in terms of communication channels for information seeking (i.e., typology of media), sources of advices, and sources of influence on food choices at interpersonal as well as environmental/community level.

The last section investigated respondents' self-perception both as individuals (i.e., physical shape) and as part of a social network (i.e., perception about being loved by family and friends). Sociodemographic information was also collected. The first column of Tables 1-6 includes a list of the variables used in this work.

Before executing the large-scale survey, the questionnaire was tested and piloted with 49 high school students. Adjustments were made, and consensus on the final questionnaire was reached based on both adolescents' and experts' opinions.

\section{Data Analysis}

The authors built an individual-level score of adherence to healthy diet recommendations of Tuscany and WHO (ARS Toscana, 2008; WHO, 2015), according to the frequency of consumption of each specific food product (food score [FS]). The FS presents a minimum value of -6 , which indicates the least adherence to recommendations, and a maximum value of 27.5 , which represents the highest adherence. 
Additionally, three indexes were developed based on the answers to the three multiple-choice questions about the most used:

1. source of food-related information (Internet, books or magazines, mobile applications, social networks, TV programs, none of these),

2. source of advices on food (friends, family, sport trainer, family doctor, teacher, other people), and

3. source of influence on food choices (friends, family, sport trainer, family doctor, other people).

Subsequently, a CA was performed on the basis of the three indexes described above, using an agglomerative hierarchical method (Ward's linkage, L2 similarity measure) to identify subgroups of respondents (Cannavò \& Frudà, 2007; Punj \& Steward, 1983; Swenson et al., 2018).

A five-cluster solution worked the best, based on the pseudo $F$-statistic (Calinski \& Harasbasz, 1974). The clusters were then tested by investigating differences in intrapersonal, interpersonal and community/environmental, and societal factors (see Tables 3-6). The $\chi^{2}$ test and $F$ test for the analysis of variance were used to characterize the clusters. All the analyses have been performed using the software STATA v. 14.1.

\section{Results}

\section{Sample Characteristics}

As shown in Table 1 in the column "Total sample," 4,749 students aged 15-18 completed the questionnaires: more than half of them were female (57\%); most of them come from a high $(48.6 \%)$ or medium educated family (39.8\%), almost all from a liceo high school. ${ }^{2}$ The average adolescents' FS is equally distant from the max and the min value of the scale (FS mean $=11.73, S D=4.40)$. Indeed, respondents' lifestyle habits are not still fully adherent to the experts' recommendations. In general, most of the teenagers reported to be influenced by the family $(60.8 \%)$, while the family doctor was the least selected as influence source $(8.6 \%) ; 26.6 \%$ of adolescents declared to not being influenced by anyone. Looking at the sources of advice, the adolescents mainly declared to prefer the family doctor (73.2\%) together with the family (51.9\%). The least preferred source of suggestions is the schoolteacher $(7.6 \%$, selected prevalently from males $-p<.001)$. Internet is the most diffused source of information among teenagers $(72.5 \%)$, excluding the online social networks that are the least reported channel for food information $(6.8 \%)$.

Analyzing data by sex, it emerged that females eat better $(p<.001)$ and perceive a stronger influence from peers, while males from sport trainers $(p<.001)$. However, only males consider peers and trainers as a trusted source of advices $(p<.001)$.

Regarding the information channels, while boys predominantly tend to use only the Internet $(p<.01)$, girls tend to use from two to four different information channels $(p<.01)$, and mainly books $(p<.001)$, besides the Internet.

On the intrapersonal level, males declare to like their selves more than females do $(p<.001)$ and do not care neither about their weight $(p<.001)$ nor about what they eat $(p<.001)$. Females tend to be on diet more than males and perceive their selves fattier than they really are on the base of their body mass index (BMI; $p<.001)$. More details on sample descriptive variables are available in Tables $1-6$.

\section{Interpretation and Description of Segments}

By performing the CA, the authors identified five distinct clusters that differ in terms of openness to accept advices, influence perception, and food information searching behaviors. Tables $2-6$ contain the detailed results of the CA. 


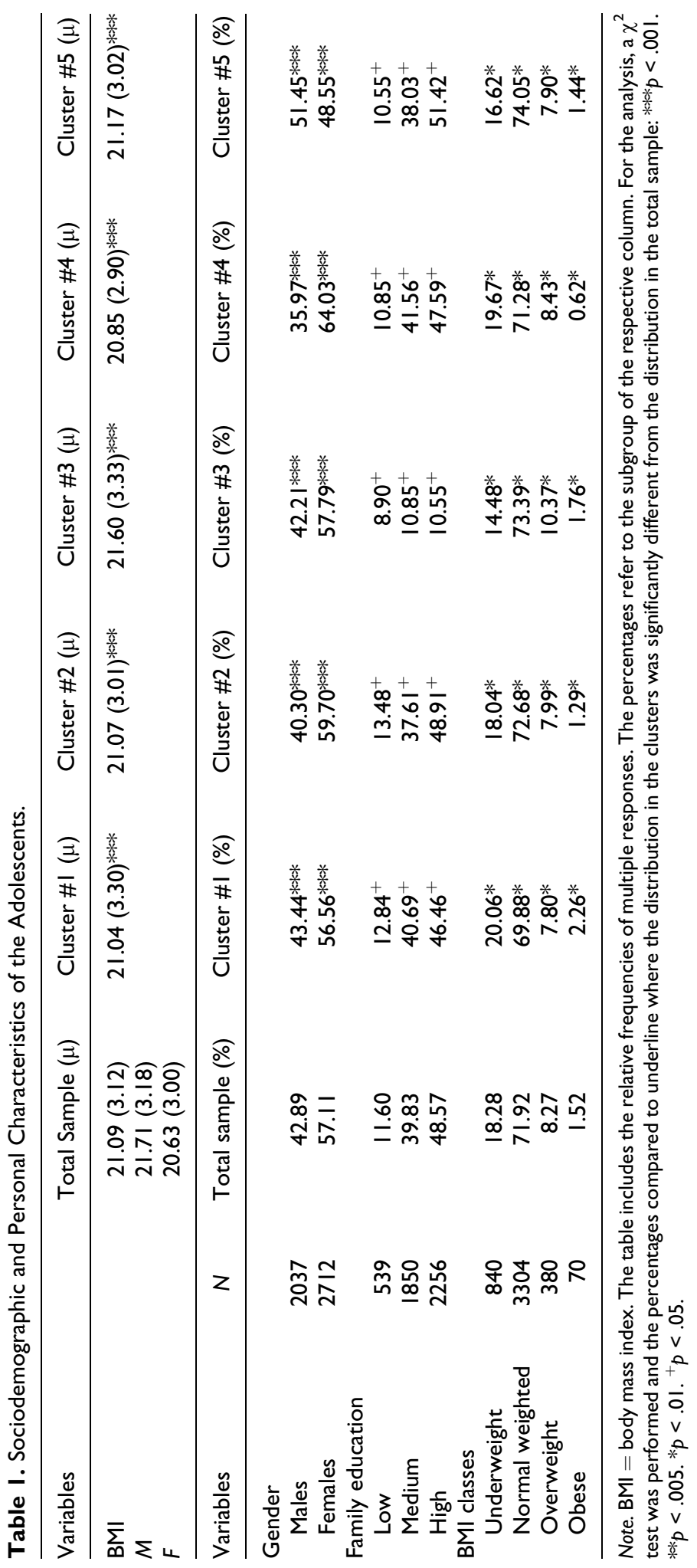


Table 2. Clustering Variables.

\begin{tabular}{|c|c|c|c|c|c|c|c|}
\hline Variables & $N$ & $\begin{array}{c}\text { Total } \\
\text { Sample (\%) }\end{array}$ & $\begin{array}{l}\text { Cluster } \\
\text { \#I (\%) }\end{array}$ & $\begin{array}{l}\text { Cluster } \\
\# 2 \text { (\%) }\end{array}$ & $\begin{array}{l}\text { Cluster } \\
\text { \#3 (\%) }\end{array}$ & $\begin{array}{l}\text { Cluster } \\
\# 4 \text { (\%) }\end{array}$ & $\begin{array}{l}\text { Cluster } \\
\# 5 \text { (\%) }\end{array}$ \\
\hline \multicolumn{8}{|l|}{ Acceptance of advices on food } \\
\hline Accept advices from $<2$ person & 1915 & 40.32 & $100 * * *$ & $0.13 * * *$ & $30.96 * * *$ & $33.17 * * *$ & $0 * * *$ \\
\hline Accept advices from 2 persons & 1625 & 34.22 & $0 * * *$ & $99.87 * * *$ & $54.03 * * *$ & $54.01 * * *$ & $0 * * *$ \\
\hline Accept advices from 3-4 persons & 1108 & 23.33 & $0 * * *$ & $0 * * *$ & $|5.0| * * *$ & $12.32 * * *$ & $90.41 * * *$ \\
\hline Accept advices from $>4$ persons & 101 & 2.13 & $0 * * *$ & $0 * * *$ & $0 * * *$ & $0.50 * * *$ & $9.59 * * *$ \\
\hline \multicolumn{8}{|l|}{ Influence on food choices } \\
\hline Influenced by $<2$ persons & 3612 & 76.06 & $100 * * *$ & $100 * * *$ & $0 * * *$ & $72.85 * * *$ & $66.73 * * *$ \\
\hline Influenced by 2 persons & 956 & 20.13 & $0 * * *$ & $0 * * *$ & $70.92 * * *$ & $25.65 * * *$ & $32.17 * * *$ \\
\hline Influenced by $>2$ persons & 181 & 3.81 & $0 * * *$ & $0 * * *$ & $29.08 * * *$ & $1.50 * * *$ & $1.10 * * *$ \\
\hline \multicolumn{8}{|c|}{ Search channels for information about food } \\
\hline Searching on $<2$ channels & 3294 & 69.36 & $100 * * *$ & $100 * * *$ & $87.43 * * *$ & $0 * * *$ & $61.04 * * *$ \\
\hline Searching on 2 channels & 1062 & 22.36 & $0 * * *$ & $0 * * *$ & $9.76 * * *$ & $65.73 * * *$ & $35.36 * * *$ \\
\hline Searching on 3-4 channels & 370 & 7.79 & $0 * * *$ & $0 * * *$ & $2.81 * * *$ & $31.96 * * *$ & $3.60 * * *$ \\
\hline Searching on $<4$ channels & 23 & 0.48 & $0 * * *$ & $0 * * *$ & $0 * * *$ & $2.30 * * *$ & $0 * * *$ \\
\hline
\end{tabular}

Note. The table includes the relative frequencies of multiple responses. The percentages refer to the subgroup of the respective column. For the analysis, a $\chi^{2}$ test was performed and the percentages compared to underline where the distribution in the clusters was significantly different from the distribution in the total sample: $*_{* *} p<.00 \mathrm{I} . *^{* *} p .005 . *_{p}<.0 \mathrm{I} .{ }^{+} p<.05$.

Table 3. Socialization Factors at Interpersonal and Community Levels.

\begin{tabular}{|c|c|c|c|c|c|c|}
\hline Variables & Total Sample (\%) & Cluster \#I (\%) & Cluster \#2 (\%) & Cluster \#3 (\%) & Cluster \#4 (\%) & Cluster \#5 (\%) \\
\hline \multicolumn{7}{|c|}{ Who influences their food choices } \\
\hline Friends & 13.18 & $4.09 * * *$ & $3.13 * * *$ & $46.34 * * *$ & $15.63 * * *$ & $13.99 * * *$ \\
\hline Family & 60.79 & $43.51 * * *$ & $54.69 * * *$ & $91.37 * * *$ & $61.32 * * *$ & $73.33^{* * *}$ \\
\hline Trainer & 10.74 & $2.89 * * *$ & $3.25 * * *$ & $41.65^{* * *}$ & $8.52 * * *$ & $13.59 * * *$ \\
\hline Physician & 8.61 & $2.89 * * *$ & $2.13^{* * *}$ & $35.65 * * *$ & $8.32 * * *$ & $7.79 * * *$ \\
\hline \multicolumn{7}{|c|}{ From whom they would accept advices on food } \\
\hline Friends & 12.34 & $3.88 * * *$ & $7.13 * * *$ & $10.69 * * *$ & $10.42^{* * *}$ & $31.27^{* * * *}$ \\
\hline Family & 51.88 & 23.06 *** & $59.32 * * *$ & $44.47 * * *$ & $50.20 * * *$ & $92.41 * * *$ \\
\hline Trainer & 41.06 & $12.98 * * *$ & $39.92 * * *$ & $48.22^{* * *}$ & $34.67 * * *$ & $84.32^{* * *}$ \\
\hline Physician & 73.24 & $47.46^{* * *}$ & $86.23 * * *$ & $75.05^{* * *}$ & $75.45^{* * * *}$ & $96.20 * * *$ \\
\hline Teacher & 7.64 & $0.71 * * *$ & $2.63 * * *$ & $4.50 * * *$ & 4.31 *** & $26.47 * * *$ \\
\hline
\end{tabular}

Note. The table includes the relative frequencies of multiple responses. The percentages refer to the subgroup of the respective column. For the analysis, a $\chi^{2}$ test was performed and the percentages compared to underline where the distribution in the clusters was significantly different from the distribution in the total sample: ${ }^{* * *} p<.00 \mathrm{I} .{ }^{* *} p<.005 .{ }^{*} p<.01 .{ }^{+} p<.05$.

To summarize the findings, teenagers in Cluster \#1 are more likely than the others to be completely closed off toward other people considering both the environmental and interpersonal levels of food socialization. They neither perceive any external influence nor accept advices on their food-related behaviors. At intrapersonal level, they present a negative pattern in relation to the FWB (i.e., selfesteem, sense of being loved). They present the worst dietary pattern among the five groups, with a very high consumption of alcohol and several binge-drinking experiences $(p<.001)$.

The variables characterizing teenagers in Cluster \#2 at intrapersonal level are quite good. These adolescents' decision-making process is characterized by an openness to people's suggestions at interpersonal (family only) and community (family physician only) levels, but without the perception of a real influence by anyone. Teenagers in this group have the best dietary score $(p<.001)$. 
Table 4. Socialization Factors at Societal Level (Media Exposure).

\begin{tabular}{lcccccc}
\hline \multicolumn{7}{c}{ Total } \\
Variables & Sample (\%) & Cluster \#I (\%) & Cluster \#2 (\%) & Cluster \#3 (\%) & Cluster \#4 (\%) & Cluster \#5 (\%) \\
\hline Where they search information about food & & & & & \\
Internet & 72.48 & $59.73^{* * *}$ & $63.08^{* * *}$ & $64.54^{* * *}$ & $94.49 * * *$ & $80.32^{* * * *}$ \\
Books & 21.71 & $7.26^{* * *}$ & $5.38^{* * *}$ & $15.01 * * *$ & $56.51^{* * * *}$ & $24.08^{* * * *}$ \\
APPs & 9.10 & $1.83^{* * *}$ & $1.25^{* * *}$ & $3.00^{* * *}$ & $29.86^{* * *}$ & $8.19 * * *$ \\
Social networks & 6.80 & $1.62^{* * *}$ & $0.88^{* * *}$ & $3.19^{* * *}$ & $23.75^{* * *}$ & $3.90^{* * * *}$ \\
TV & 12.32 & $1.90^{* * *}$ & $1.00^{* * *}$ & $5.07^{* * *}$ & $40.38^{* * *}$ & $11.99 * * *$ \\
\hline
\end{tabular}

Note. The table includes the relative frequencies of multiple responses. The percentages refer to the subgroup of the respective column. For the analysis, a $\chi^{2}$ test was performed and the percentages compared to underline where the distribution in the clusters was significantly different from the distribution in the total sample: $*_{* *} p<.001 . *^{*} p<.005 . *_{p}<.01 .{ }^{+} p<.05$.

Adolescents in Cluster \#3, on their side, feel a strong influence by several different people both at community (trainer and family doctor) and at interpersonal (family and friends) levels, also accepting advices by the people cited at community level and searching for information mainly or only on the Internet. At the intrapersonal level, they show a medium self-esteem level and feel to be enough loved. Their FS is quite good, except for the alcohol consumption $(p<.001)$.

The adolescents from Cluster \#4 present a low level of self-esteem and sense of being loved (intrapersonal level) and are more likely to be influenced from people of the interpersonal domain (family and peers) and to accept advices only from the family doctor (community level). However, their distinctive characteristic is that they are greedy searchers of food information using several communication channels as Internet and books and report a high exposure to TV programs on food. Their food habit pattern is mediocre $(p<.001)$ with some exceptions: They are overrepresented in the categories of adolescents eating fruit and vegetable every day $(p<.001)$.

Teenagers in Cluster \#5 are completely open to influences and advices at all the food socialization levels, with the most positive pattern of the variables at the intrapersonal level (i.e., self-esteem, sense of being loved). Their eating habits are pretty good among the clusters $(p<.001)$. Comparing the clusters more in detail, additional findings emerged. The adolescents' clusters characterized by a greater openness to people's suggestions $(\# 2, \# 5)$ also report better FS.

Clusters \#1 and \#5 include the largest presence of boys but are deeply different not only in relation to lifestyle habits. Cluster \#1 comprises a great number of adolescents that seem to be unattainable by anyone, untouched by any lifestyle-related topic. Otherwise, Cluster \#5 collects the majority of adolescents who seem extremely positive in respect to the various aspects of lifestyle (i.e., food, sport, physical activity), without contradictions or excesses in their reported behaviors. They are also well predisposed to the others' influences and advices, including a modest trust toward teachers, while the other adolescents reported distrusted behaviors toward them. The closeness to advices and influences of Cluster \#1 seems to be particularly related to individuals and social networks different from the family. The self-esteem dimension (intrapersonal level) also distinguishes these two clusters (\#1, \#5), with an overrepresentation in Cluster \#1 of adolescents who do not feel to be loved neither by family nor by friends. However, they are aware of their body shape condition, as the teenagers in Cluster \#5.

The influence of the intrapersonal aspects also emerged comparing other two clusters (\#3, \#4) with a prevalence of girls. In these clusters, in addition to the wrong perception of their selves, adolescents reported to give a great importance to weight (overestimating it) and to think more to what they eat, in comparison with the other groups. Adolescents in the three clusters with a prevalence of females (\#2, \#3, \#4) have a higher sensitivity to their body image, with a diffused incoherence between selfperception and BMI. This is mirrored in their relationship with food and in the three different food 


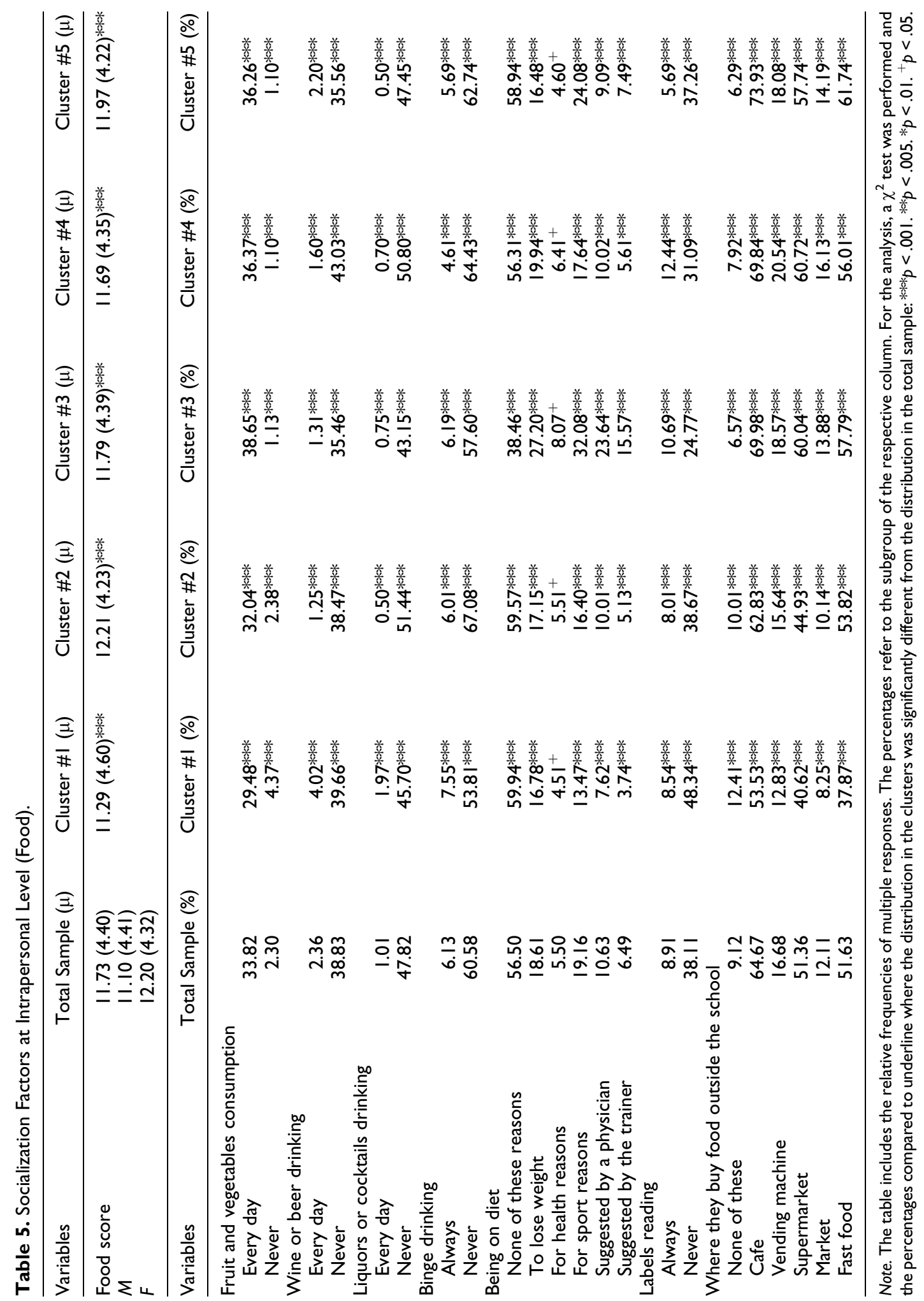


Table 6. Socialization Factors at Intrapersonal Level (Self-Esteem).

\begin{tabular}{|c|c|c|c|c|c|c|}
\hline Variables & $\begin{array}{c}\text { Total } \\
\text { Sample (\%) }\end{array}$ & $\begin{array}{l}\text { Cluster } \\
\# I \text { (\%) }\end{array}$ & $\begin{array}{l}\text { Cluster } \\
\# 2(\%)\end{array}$ & $\begin{array}{l}\text { Cluster } \\
\# 3(\%)\end{array}$ & $\begin{array}{l}\text { Cluster } \\
\# 4(\%)\end{array}$ & $\begin{array}{l}\text { Cluster } \\
\# 5 \text { (\%) }\end{array}$ \\
\hline \multicolumn{7}{|c|}{ Self-perception about weight } \\
\hline Underweight & 7.92 & $10.30 * *$ & $7.38 * *$ & $4.69 * *$ & $7.82 * *$ & $6.79 * *$ \\
\hline Normal weighted & 70.79 & $69.11 * *$ & 70.96** & $69.79 * *$ & $70.84 * *$ & $73.53^{* *}$ \\
\hline Overweight & 19.94 & $18.83^{* *}$ & $20.28 * *$ & $24.02 * *$ & $20.24 * *$ & $18.78^{* *}$ \\
\hline Obese & 1.35 & 1.76 ** & $1.38^{* * *}$ & $1.50 * *$ & $1.10 * *$ & $0.90 * *$ \\
\hline \multicolumn{7}{|l|}{ Like myself } \\
\hline Completely & 9.84 & 11.36 ** & $9.02 * *$ & $8.63 * *$ & $9.02 * *$ & $9.79 * *$ \\
\hline Not at all & 8.07 & $9.95^{* *}$ & $6.52^{* *}$ & $9.57^{* *}$ & $8.12 * *$ & $5.79 * *$ \\
\hline \multicolumn{7}{|c|}{ How much they care about weight } \\
\hline A lot & $22.4 \mathrm{I}$ & $22.36 * * *$ & $20.15^{* * * *}$ & $27.20 * * *$ & $23.17 * * *$ & $20.98 * * *$ \\
\hline Not at all & 5.14 & $7.55^{* * * *}$ & $4.51 * * * *$ & $3.00 * * *$ & $3.81 * * *$ & $4.70 * * *$ \\
\hline \multicolumn{7}{|c|}{ Think about what to eat } \\
\hline Often/Always & 38.05 & $32.02 * * *$ & $37.92 * * *$ & $43.34 * * *$ & $43.19 * * *$ & $38.76 * * *$ \\
\hline Never & 6.25 & $11.50 * * *$ & $4.26 * * * *$ & $3.00 * * *$ & $4.01 * * *$ & $4.40 * * *$ \\
\hline \multicolumn{7}{|l|}{ Loved from my family } \\
\hline Completely & 68.64 & $64.88 * * * *$ & $73.34 * * *$ & $63.79 * * *$ & $67.13^{* * * *}$ & $74.30 * * *$ \\
\hline Not at all & 1.64 & $2.82 * * *$ & $0.75^{* * * *}$ & $1.31 * * *$ & $1.50 * * *$ & $1.00 * * *$ \\
\hline \multicolumn{7}{|c|}{ Loved from my friends } \\
\hline Completely & 45.50 & $42.03 * *$ & $49.06 * *$ & $42.96 * *$ & $45.28 * *$ & $49.15^{* *}$ \\
\hline Not at all & 1.37 & $2.33^{* * *}$ & $0.50^{* *}$ & $1.13 * *$ & $\left.1.4\right|^{* *}$ & $0.80 * *$ \\
\hline
\end{tabular}

Note. The table includes the relative frequencies of multiple responses. The percentages refer to the subgroup of the respective column. For the analysis, a $\chi^{2}$ test was performed and the percentages compared to underline where the distribution in the clusters was significantly different from the distribution in the total sample: $*^{* *} p<.00 \mathrm{I} .{ }^{* *} p<.005 .{ }^{*} p<.0 \mathrm{I}$. ${ }^{+} p<.05$.

socialization patterns that emerge: (1) feeling strongly influenced by different people of their different social networks (\#3), (2) considering acceptable suggestions from several different types of individuals, without feeling to be influenced by them (\#2), and (3) using media, not people, as the most important source of information (\#4).

Adolescents in Cluster \#3, who feel to be strongly influenced by several different types of individuals in their networks, also present inconsistent food behaviors, not eating bad but being on diet and, at the same time, heavily consuming alcohol.

\section{Discussion}

This study clustered adolescents around food socialization factors, rather than food behaviors, in order to inform policy makers and social marketers on how to target interventions also considering the web of influences on teenagers' behaviors. By clustering adolescents on the basis of three food socialization indicators, the authors expanded the research conducted to date on adolescents' food choice patterns, by describing significant differences not only in terms of influence from their social networks at interpersonal and community level but also in terms of larger influence from new and traditional media.

The results of the CA performed in this study confirm that adolescents are not a monolithic category of people, despite who responded to the survey have some sociodemographic characteristics in common (i.e., level of education of parents, type of high school attended, geographical features, and related food culture). 
According to the literature (Aura et al., 2016), males and females have some different lifestyle habits, and this is confirmed both at the total sample level and within the clusters. Nevertheless, the present analysis shows that there are relevant differences also within the clusters with similar gender composition: for example, clusters $\# 1$ and $\# 5$ are prevalently masculine, but at the antipodes. These two clusters, with very different lifestyle habits, differ at intrapersonal level (i.e., self-esteem, sense of being loved) and in their relationships with other people different from family members. In a difficult time of adaptation to social complexity, as the adolescence is, emotional development seems to be an important step in the acquisition of health and human capital (Patton et al., 2016), while school and family can be protective systems against risky and unhealthy habits (Cwik et al., 2017).

Also in relation to the intrapersonal factors, the literature highlights the association between weight, what to eat, and, in general, sensitivity to body shape with the wrong perception of body and BMI (Shroff, \& Thompson, 2006). Moreover, it was demonstrated that an obsessive thinking to food might cause a boomerang effect, leading to select non-healthy food (M. Bublitz, Peracchio, \& Block, 2010). This can partially explain why adolescents in clusters \#3 and \#4 present incongruous eating behaviors (e.g., eating well, but drinking a lot). The contradictory behaviors may also be explained by the need to be well judged by different individuals in their networks, to find more social support, or to be more accepted (Burnkrant \& Cousineau, 1975).

The high FS registered by the clusters that are more open to advices (\#2, \#5) confirms that social influence and support may have a positive impact on adolescents' food behaviors (Cwik et al., 2017; Parkinson et al., 2016; Viner et al., 2012). As stated, family and school are protective factors for adolescents, while poorer health and well-being are linked to an early autonomy and disengagement from parents and educational systems (Dishion et al., 2004). An interesting result is that neither peers nor teachers were chosen by adolescents as important sources of suggestions or information.

Looking at peers, the result may be affected by the adolescents' perception of peers' influence on their food choices and by a progressive growth in the adolescents' capacity to resist peer influence (Albert, Chein, \& Steinberg, 2013). However, there is evidence in literature about the importance of peer pressure for food choices in adolescence (Brown, 2004; Salvy et al., 2012; Somerville, 2013; Steinberg \& Monahan, 2007).

The marginal role that adolescents accord to teachers in relation to their food behaviors is an important finding, considering that the school is recognized as a valuable environment for promoting social marketing interventions addressing healthy behaviors, often by using teachers as "messengers," overall (Patton et al., 2016) and, in particular, in Italy (Giannotta \& Weichold, 2016). Only a very close relationship between students and teachers was found to be beneficial in changing teenagers' behaviors and reducing their risky lifestyle-related behaviors (Fletcher et al., 2008; Bonell et al., 2019).

In relation to the media exposure, teenagers who use a number of different information channels (Cluster \#4) present a low FS. Considering that more and better food knowledge can lead to better food choices (Vidgen \& Gallegos, 2014; Worsley, 2002), this result may be interpreted in two manners. The increase in food-related information exposure and, eventually, of food knowledge alone is insufficient to produce food literacy really improving food behaviors (Block et al., 2011; Parkinson et al., 2016). Adolescents' information seeking seems to follow the "confirmatory information search strategy" that does not increase their objective food knowledge, but mainly the subjective one that tends to be confirmatory of the habitual food behaviors (Moorman, Diehl, Brinberg, \& Kidwell, 2004; Verplanken \& Wood, 2006). Moreover, adolescents in Cluster \#4 may be strongly influenced by commercial food marketing, when they search information on different media (J. C. Bublitz, 2013). At the same time, the overrepresentation in this cluster of adolescents who eat almost five portions of fruits and vegetables a day and who do not consume alcohol may be explained by the "food motivation": The consideration of additional food information, like as labels and ingredients, can be linked to healthier food behaviors (J. C. Bublitz, 2013). 


\section{Implications for Policy and Practice}

As a result of this work, it emerges the need for a careful segmentation including influence factors in the food socialization domain, when designing social marketing interventions to effectively change teenagers' lifestyle. For example, working with socially marginalized or more vulnerable adolescents (as teenagers in the Cluster \#1) on the building of "intrapersonal skills" may produce adaptive advantages and improve their sense of agency (Patton et al., 2016). Family and school represent the two most important enabling and supporting systems to enhance adolescents' emotional development and, thus, the intrapersonal and interpersonal aspects that influence their FWB (Cwik et al., 2017). At the same time, teenagers from low socioeconomic status families could lack family and social support or could be part of networks that negatively influence their behaviors (Parkinson et al., 2016). In this case, understanding the web of relationships and offering a community-based intervention can facilitate the involvement of these groups in processes of behavioral change (Luca et al., 2016). Moreover, interventions for supporting the adolescents' FWB should go beyond the individual adolescent, targeting also families and developing more structural interventions aimed at affecting social and environmental determinants of adolescents' choices (Parkinson et al., 2016; Spotswood \& Tapp, 2013; Wymer, 2011). Interventions and policies aiming at changing behaviors should be designed as inter-sectoral actions, give coherent stimuli, and reorganize choice environment. These integrated strategies can improve adolescents' food behaviors, for example, by facilitating the access to fresh food in the places where they generally live in.

Adolescents broadly recognize the family as a primary source of influence and advices. However, teenagers who are strongly exposed to media and social media (like the Cluster \#4 teenagers), but not influenced at community and interpersonal levels, need to be targeted by initiative aimed at developing the positive power of influence and advices coming from a broader network of people, as well as by actions that use media as one of the main channels.

School-based interventions should be built on positive and personal relationships between teachers and students, by analyzing individual interpersonal factors that may affect their effectiveness. In the absence of these fundamental bases, initiatives on health and well-being promotion that use teachers as the main communication source could fail.

Recently, peer-to-peer actions have been object of great interest: Participative and horizontal interventions can be effective in improving teenagers' food knowledge and attitudes (Aral \& Walker, 2011; Foley et al., 2017; Aceves-Martins et al., 2017). However, also peer-to-peer actions should be implemented considering the domains in which peer influence better works and identifying those peers within the network being good at promoting the program (Luca et al., 2016; Scott, 2000). For example, after an "enabling" work on skills, knowledge, and capabilities development (Pennucci et al., 2019) with teenagers like the Cluster \#5 ones, these latter could be effective at persuading and supporting other teenagers - similar to Cluster \#1 teenagers - in doing healthier activities or in improving their self-esteem.

A crucial role in promoting healthier lifestyle habits could be played by family doctors, seen by adolescents as a possible trusted source of information and advices about food and physical activity. This implies a cultural rethinking of the doctor's role, overcoming the traditional idea of the healthcare service provider in an asymmetric patient-doctor relationship. The family doctor can be a facilitator of teenagers' education and activation and a source of positive lifestyle-related nudges (Pennucci et al., 2019).

\section{Limitations and Future Research}

Data used for clustering teenagers are self-reported by respondents. This could produce misinterpretation of the questions posed and little or decreasing survey attention. The convenience sample could 
produce an additional bias. However, the great number of respondents (more than 4,700, reaching a size of around 500 adolescents for each Tuscan province Tuscany) can mitigate these potential biases. Moreover, the survey was held in a single Italian region, where the resident population is quite large. As a further development, this study could be replicated in other geographic contexts, with different food culture, social and cultural norms, as well as socialization networks and agents. Meaningful segmentation should also include adolescents with different socioeconomic characteristics. Future research can be done including additional domains of teenagers' lifestyle, such as physical activity, or analyzing environmental features that can affect their behaviors, or exploring determinants and preferences related to their food choices, using experimental methods.

\section{Conclusions}

The findings of this research show that prospectively clustering adolescent around food socialization factors can help in identifying relevant differences in teenagers' behaviors, to be taken into consideration when designing and targeting a social marketing program. By means of different socialization agents, networks, and channels as well, social marketing interventions can more effectively improve teenagers' healthy habits and establish a good FWB. As showed in the Results section, adolescents are not a homogeneous group, also in relation to how the various webs of influences can act on their choices. The findings of this study show that adolescents who reported a broader food socialization at all levels (intrapersonal, interpersonal, environmental-community, and societal) present also a good FWB. Additionally, a wider exposure to different influences at different levels in different environments, as well as the self-esteem and emotional development, can represent positive and enabling elements in the adolescents' adoption of "well-balanced" lifestyle behaviors. In this sense, it is relevant working differently on different food socialization patterns, in order to improve the effectiveness of social marketing intervention in promoting healthy conducts toward teenagers.

\section{Authors' Contributions}

All the authors were involved in designing the overall contents of this paper. SDR coordinated the beFood project. FP performed the analyses, under the scientific supervision of CS. All the authors were responsible for writing the manuscript, with specific contributions: introduction (SDR and CS); background (SDR); results (FP). All the authors were involved in interpreting the findings, writing the discussions and approving the final manuscript.

\section{Declaration of Conflicting Interests}

The author(s) declared no potential conflicts of interest with respect to the research, authorship, and/or publication of this article.

\section{Funding}

The author(s) disclosed receipt of the following financial support for the research, authorship, and/or publication of this article: The beFood project was financed by the Tuscany Region.

\section{ORCID iD}

Sabina De Rosis (D) https://orcid.org/0000-0002-8781-401X

\section{Notes}

1. Individuals aged around 16-17 years are defined as late adolescents (Story, Neumark-Sztainer, \& French, 2002).

2. The Italian upper secondary school is divided into two main categories: one comprises high schools that provide a more academic and general training, the so-called liceo; the other category includes istituti, where more practical and technical disciplines are taught. 


\section{References}

Aceves-Martins, M., Llauradó, E., Tarro, L., Moriña, D., Papell-Garcia, I., Prades-Tena, J., . . Giralt, M. (2017). A school-based, peer-led, social marketing intervention to engage Spanish adolescents in a healthy lifestyle ("We Are cool"- - som la pera study): A parallel-cluster randomized controlled study. Childhood Obesity, 13, 300-313.

Albert, D., Chein, J., \& Steinberg, L. (2013). The teenage brain. Current Directions in Psychological Science, 22, $114-120$.

Andreasen, A. R. (2002). Marketing social marketing in the social change marketplace. Journal of Public Policy \& Marketing, 21, 3-13.

Aral, S., \& Walker, D. (2011), Creating social contagion through viral product design: A randomized trial of peer influence in networks. Management Science, 57, 1623-1639.

Aura, A., Sormunen, M., \& Tossavainen, K. (2016). The relation of socio-ecological factors to adolescents' health-related behaviour: A literature review. Health Education, 116, 177-201.

Berg, C. J., Ling, P. M., Guo, H., Windle, M., Thomas, J. L., Ahluwalia, J. S., \& An, L. C. (2010). Using market research to characterize college students and identify targets for influencing health behaviors. Social Marketing Quarterly, 16, 41-69.

Berti, A., Gnaulati, L., Innocenti, F., Lazzeretti, M., Silvestri, C., \& Voller, F. (2018). Comportamenti alla guida e stili di vita a rischio nei ragazzi in Toscana-rapporto EDIT. [Driving behaviors and risky lifestyles in teenagers in Tuscany]. Florence, Italy: ARS Toscana.

Block, L. G., Grier, S. A., Childers, T. L., Davis, B., Ebert, J. E., Kumanyika, S., . . van Ginkel Bieshaar, M. N. (2011). From nutrients to nurturance: A conceptual introduction to food well-being. Journal of Public Policy \& Marketing, 30, 5-13.

Blum, R. W., Bastos, F. I., Kabiru, C. W., \& Le, L. C. (2012). Adolescent health in the 21 st century. The Lancet, $379,1567-1568$.

Bonell, C., Beaumont, E., Dodd, M., Elbourne, D. R., Bevilacqua, L., Mathiot, A., . . Allen, E. (2019). Effects of school environments on student risk-behaviours: evidence from a longitudinal study of secondary schools in England. J Epidemiol Community Health, 73, 502-508.

Brennan, L., Previte, J., \& Fry, M. L. (2016). Social marketing's consumer myopia: Applying a behavioural ecological model to address wicked problems. Journal of Social Marketing, 6, 219-239.

Brown, B. B. (2004). Adolescents' relationships with peers. In R. Lerner \& L. Steinberg (Eds.), Handbook of adolescent psychology (pp. 363-394). New York, NY: Wiley.

Bublitz, J. C. (2013). My mind is mine?! Cognitive liberty as a legal concept. In E. Hildt \& A. G. Franke (Eds.), Cognitive enhancement: An interdisciplinary perspective (pp. 233-264). Dordrecht, the Netherlands: Springer.

Bublitz, M., Peracchio, L., \& Block, L. G. (2010). Why did I eat that? Perspectives on food decision making and dietary restraint. Journal of Consumer Psychology, 20, 239-258.

Burke, V., Milligan, R. A. K., Beilin, L. J., Dunbar, D., Spencer, M., Balde, E., \& Gracey, M. P. (1997). Clustering of health-related behaviors among 18-year-old Australians. Preventive Medicine, 26, 724-733.

Burnkrant, R. E., \& Cousineau, A. (1975). Informational and normative social influence in buyer behavior. Journal of Consumer Research, 2, 206-215.

Calinski, T., \& Harabasz, J. (1974). A dendrite method for cluster analysis. Communications in Statistics, 3, 1-27.

Campain, A. C., Morgan, M. V., Evans, R. W., Ugoni, A., Adams, G. G., Conn, J. A., \& Watson, M. J. (2003). Sugar-starch combinations in food and the relationship to dental caries in low-risk adolescents. European Journal Oral Sciences, 111, 316-325.

Cannavò, L., \& Frudà, L. (2007). Ricerca sociale. Dall'analisi esplorativa al data mining III ed. [Social research. From exploratory analysis to data mining]. Rome, Italy: Carocci editore.

Catalano, R. F., Fagan, A. A., Gavin, L. E., Greenberg, M. T., Irwin, C. E. Jr., Ross, D. A., \& Shek, D. T. (2012). Worldwide application of prevention science in adolescent health. The Lancet, 379, 1653-1664.

Churchill, G. A. Jr., \& Moschis, G. P. (1979). Television and interpersonal influences on adolescent consumer learning. Journal of Consumer Research, 6, 23-35. 
Coffano, E. (2010). Guadagnare salute in adolescenza: Ricognizione delle esperienze di prevenzione e promozione della salute in Italia - Report finale [Gaining Health: experiences of prevention and health promotion in Italy, Final Report]. Retrieved November 10, 2010. Chapter 4393/2004 - CCM.

Contento, I. R., Michela, J. L., \& Goldberg, C. J. (1988). Food choice among adolescents: Population segmentation by motivations. Journal of Nutrition Education, 20, 289-298.

Counihan, C. M. (2004). Around the Tuscan Table: Food, family, and gender in twentieth century. Florence, Italy: Routledge.

Cramer, S. (2016). Food should be labelled with the exercise needed to expend its calories. British Medical Journal, 353, i1856.

Cwik, M. F., Rosenstock, S., Tingey, L., Redmond, C., Goklish, N., Larzelere-Hinton, F., \& Barlow, A. (2017). Exploration of pathways to binge drinking among American Indian adolescents. Prevention Science, 18, $545-554$.

Dibb, S. (2017). Changing times for social marketing segmentation. In T. Dietrich, S. Rundle-Thiele, \& K. Kubacki (Eds.), Segmentation in social marketing (pp. 41-59). Singapore: Springer.

Dick, B., \& Ferguson, B. J. (2015). Health for the world's adolescents: A second chance in the second decade. Journal of Adolescent Health, 56, 3-6.

Dietrich, T. (2017). Segmentation in social marketing: Five steps to success. In T. Dietrich, S. Rundle-Thiele, \& K. Kubacki (Eds.), Segmentation in social marketing (77-92). Singapore: Springer.

Dietrich, T., Rundle-Thiele, S., \& Kubacki, K. (2017). Segmentation in social marketing. Berlin, Germany: Springer.

Dietrich, T., Rundle-Thiele, S., Leo, C., \& Connor, J. (2015). One size (never) fits all: Segment differences observed following a school-based alcohol social marketing program. Journal of School Health, 85, 251-259

Dietrich, T., Rundle-Thiele, S., Schuster, L., \& Connor, J. P. (2016). A systematic literature review of alcohol education programmes in middle and high school settings (2000-2014). Health Education, 116, 50-68.

Dishion, T. J., Nelson, S. E., \& Bullock, B. M. (2004). Premature adolescent autonomy: Parent disengagement and deviant peer process in the amplification of problem behaviour. Journal of Adolescence, 27, 515-530.

Duane, S., Domegan, C., McHugh, P., \& Devaney, M. (2016). From restricted to complex exchange and beyond: social marketing's change agenda. Journal of Marketing Management, 32, 856-876.

Edit—Agenzia Regionale di Sanità della Toscana. (2015). Comportamenti alla guida e stili di vita a rischio nei ragazzi in toscana [Digital Edition]. Retrieved from https://www.ars.toscana.it/it/edit.html

Fletcher, A., \& Bonell, C. (2008). Detaching youth work to reduce drug and alcohol-related harm. Public Policy Research, 15, 217-223. doi:10.1111/j.1744-540x.2008.00543.x

Foley, B. C., Shrewsbury, V. A., Hardy, L. L., Flood, V. M., Byth, K., \& Shah, S. (2017). Evaluation of a peer education program on student leaders' energy balance-related behaviors. BMC Public Health, 17, 695.

Giannotta, F., Ortega, E., \& Stattin, H. (2013). An attachment parenting intervention to prevent adolescents' problem behaviors: A pilot study in Italy. Child \& Youth Care Forum, 42, 71-85.

Giannotta, F., \& Weichold, K. (2016). Evaluation of a life skills program to prevent adolescent alcohol use in two European countries: One-year follow-up. Child \& Youth Care Forum, 45, 607-624.

Gordon, R. (2013). Unlocking the potential of upstream social marketing. European Journal of Marketing, 47, 1525-1547.

Hastings, G., McDermott, L., \& Anderson, S. (2000). Whose behavior is it anyway? The broader potential of social marketing. Social Marketing Quarterly, 6, 46-58.

Hill, W. W., Beatty, S. E., \& Walsh, G. (2013). A segmentation of adolescent online users and shoppers. Journal of Services Marketing, 27, 347-360.

Hoek, J., \& Jones, S. C. (2011). Regulation, public health and social marketing: A behaviour change trinity. Journal of Social Marketing, 1, 32-44.

Jaccard, J., Blanton, H., \& Dodge, T. (2005). Peer influences on risk behavior: An analysis of the effects of a close friend. Developmental Psychology, 41, 135-147. 
Jordan, A. B., Kramer-Golinkoff, E., \& Strasburger, V. C. (2008). Does adolescent media use cause obesity and eating disorders? Adolescent Medicine: State of the Art Reviews, 19, 431-449.

Kolodinsky, J., \& Reynolds, T. (2009). Segmentation of overweight Americans and opportunities for social marketing. International Journal of Behavioral Nutrition and Physical Activity, 6, 13.

Kotler, P., \& Lee, N. (2008). Corporate social responsibility: Doing the most good for your company and your cause. Hoboken, NJ: Wiley.

Kubacki, K., Rundle-Thiele, S., Pang, B., Carins, J., Parkinson, J., Fujihira, H., \& Ronto, R. (2017). An umbrella review of the use of segmentation in social marketing interventions. In T. Dietrich, S. Rundle-Thiele, \& K. Kubacki (Eds.), Segmentation in social marketing (9-23). Singapore: Springer.

Lazzeri, G., Panatto, D., Pammolli, A., Azzolini, E., Simi, R., Meoni, V., ... Gasparini, R. (2015). Trends in overweight and obesity prevalence in Tuscan schoolchildren (2002-2012). Public Health Nutrition, 18, 3078-3085.

Lazzeri, G., Pilato, V., Pammolli, A., Simi, R., Galeone, D., Balocchini, E., \& Giacchi, M. V. (2013). Promotion of fruits and vegetables consumption: Results of a school-based intervention in a sample of 13-15 years old Italian students. International Journal of Child Health and Nutrition, 2, 326-334.

Lefebvre, R. C. (2011). An integrative model for social marketing. Journal of Social Marketing, 1, 54-72.

Lefebvre, R. C. (2013). Social marketing and social change: Strategies and tools for improving health, wellbeing, and the environment. San Francisco, CA: Jossey-Bass.

Lefebvre, R. C., \& Flora, J. A. (1988). Social marketing and public health intervention. Health Education Quarterly, 15, 299-315.

Luca, N. R., Hibbert, S., \& McDonald, R. (2016). Towards a service-dominant approach to social marketing. Marketing Theory, 16, 194-218.

Luecking, C. T., Hennink-Kaminski, H., Ihekweazu, C., Vaughn, A., Mazzucca, S., \& Ward, D. S. (2017). Social marketing approaches to nutrition and physical activity interventions in early care and education centres: A systematic review. Obesity Reviews, 18, 1425-1438.

Mishra, A., Maheswarappa, S. S., \& Colby, C. L. (2018). Technology readiness of teenagers: A consumer socialization perspective. Journal of Services Marketing, 32, 592-604.

Moorman, C., Diehl, K., Brinberg, D., \& Kidwell, B. (2004). Subjective knowledge, search locations, and consumer choice. Journal of Consumer Research, 31, 673-680.

Moschis, G. P. (1985). The role of family communication in consumer socialization of children and adolescents. Journal of Consumer Research, 11, 898-913.

Moschis, G. P., \& Churchill, G. A., Jr. (1978). Consumer socialization: A theoretical and empirical analysis. Journal of Marketing Research, 15, 599-609.

Moschis, G. P., \& Moore, R. L. (2016). Mass media and personal influences on adolescent consumer learning. In Proceedings of the 1979 Academy of Marketing Science (AMS) Annual Conference (pp. 127-131). Springer: Cham.

Moss, H., Kirby, S., \& Donodeo, F. (2009). Characterizing and reaching high-risk drinkers using audience segmentation. Alcoholism: Clinical and Experimental Research, 33, 1336-1345.

Newby, P. K., \& Tucker, K. L. (2004). Empirically derived eating patterns using factor or cluster analysis: A review. Nutrition Reviews, 62, 177-203.

Newton, J. D., Newton, F. J., Turk, T., \& Ewing, M. T. (2013). Ethical evaluation of audience segmentation in social marketing. European Journal of Marketing, 47, 1421-1438.

Niemeier, H. M., Raynor, H. A., Lloyd-Richardson, E. E., Rogers, M. L., \& Wing, R. R. (2006). Fast food consumption and breakfast skipping: Predictors of weight gain from adolescence to adulthood in a nationally representative sample. Journal of Adolescent Health, 39, 842-849.

Paek, H. J., Reber, B. H., \& Lariscy, R. W. (2011). Roles of interpersonal and media socialization agents in adolescent self-reported health literacy: A health socialization perspective. Health Education Research, 26, 131-149.

Panunzio, M. F., Antoniciello, A., Cela, E. P., Ferguson, L. R., Bucci, E., Petracca, L., .. Ugolini, G. (2010). 15-week long school-based nutritional education program to promote Italian primary schoolchildren's fruit and vegetable intake. Annali di Igiene, 22, 481-484. 
Parkinson, J., Schuster, L., \& Russell-Bennett, R. (2016). Insights into the complexity of behaviours: The MOAB framework. Journal of Social Marketing, 6, 412-427.

Patrick, H., \& Nicklas, T. A. (2005). A review of family and social determinants of children's eating patterns and diet quality. Journal of the American College of Nutrition, 24, 83-92.

Patton, G. C., Sawyer, S. M., Santelli, J. S., Ross, D. A., Afifi, R., Allen, N. B., . . Viner, R. M. (2016). Our future: A lancet commission on adolescent health and wellbeing. The Lancet, 387, 2423-2478.

Pennucci, F., De Rosis, S., Murante, A. M., \& Nuti, S. (2019). Behavioural and social sciences to enhance the efficacy of health promotion interventions: Redesigning the role of professionals and people. Behavioural Public Policy, 1-21.

Pennucci, F., De Rosis, S., \& Nuti, S. (2018). Quando promuovere stili di vita sani diventa un'esperienza professionale per gli adolescenti: Il progetto 'beFood' [When promoting healthy lifestyle becomes a professional experience for adolescents: the 'beFood' project]. Politiche Sanitarie, 19, 10-22.

Punj, G., \& Stewart, D. W. (1983). Cluster analysis in marketing research: Review and suggestions for application. Journal of Marketing Research, 20, 134-148.

Regione Toscana, ARS. (2008). La piramide alimentare toscana [Digital Edition]. Retrieved from http://www. regione.toscana.it/piramide-alimentare-toscana

Reicks, M., Banna, J., Cluskey, M., Gunther, C., Hongu, N., Richards, R., ... Wong, S. (2015). Influence of parenting practices on eating behaviors of early adolescents during independent eating occasions: Implications for obesity prevention. Nutrients, 7, 8783-8801.

Resnick, M. D., Catalano, R. F., Sawyer, S. M., Viner, R., \& Patton, G. C. (2012). Seizing the opportunities of adolescent health. The Lancet, 379, 1564-1567.

Richards, T., Coulter, A., \& Wicks, P. (2015). Time to deliver patient centred care. British Medical Journal, 350, h530.

Rose, S. A., Poynter, P. S., Anderson, J. W., Noar, S. M., \& Conigliaro, J. (2013). Physician weight loss advice and patient weight loss behavior change: A literature review and meta-analysis of survey data. International Journal of Obesity, 37, 118-128.

Salvy, S. A., de la Haye, K., \& Hermans, R. C. J. (2012), Influence of peers and friends on children's and adolescents' eating and activity behaviors. Physiology and Behavior, 106, 369-378.

Santomauro, F., Lorini, C., Tanini, T., Indiani, L., Lastrucci, V., Comodo, N., \& Bonaccorsi, G. (2014). Adherence to Mediterranean diet in a sample of Tuscan adolescents. Nutrition, 30, 1379-1383.

Scott, J. (2000). Social network analysis: A handbook. London, England: Sage.

Seiders, K., \& Petty, R. D. (2004). Obesity and the role of food marketing: A policy analysis of issues and remedies. Journal of Public Policy \& Marketing, 23, 153-169.

Shroff, H., \& Thompson, J. K. (2006) Peer influences, body-image dissatisfaction, eating dysfunction and selfesteem in adolescent girls. Journal of Health Psychology, 11, 533-551.

Snyder, L. B., Hamilton, M. A., Mitchell, E. W., Kiwanuka-Tondo, J., Fleming-Milici, F., \& Proctor, D. (2004). A meta-analysis of the effect of mediated health communication campaigns on behavior change in the United States. Journal of Health Communication, 9, 71-96.

Snyder, L. B., Milici, F. F., Slater, M., Sun, H., \& Strizhakova, Y. (2006). Effects of alcohol advertising exposure on drinking among youth. Archives of Pediatrics \& Adolescent Medicine, 160, 18-24.

Somerville, L. H. (2013). The teenage brain sensitivity to social evaluation. Current Directions Psychological Science, 22, 121-127.

Spotswood, F., \& Tapp, A. (2013). Beyond persuasion: A cultural perspective of behavior. Journal of Social Marketing, 3, 275-294.

Steinberg, L. (2008). A social neuroscience perspective on adolescent risk-taking. Developmental Review, 28, 78-106.

Steinberg, L., \& Monahan, K. C. (2007). Age differences in resistance to peer influence. Developmental Psychology, 43, 1531-1543.

Stone, M. J., Soulard, J., Migacz, S., \& Wolf, E. (2018). Elements of memorable food, drink, and culinary tourism experiences. Journal of Travel Research, 57, 1121-1132. 
Story, M., Neumark-Sztainer, D., \& French, S. A. (2002). Individual and environmental influences on adolescent eating behaviors. Journal of the American Dietetic Association, 102, S40-S51.

Suragh, T., Berg, C., \& Nehl, E. (2013). Psychographic segments of college females and males in relation to substance use behaviors. Social Marketing Quarterly, 19, 172-187.

Swenson, E. R., Bastian, N. D., \& Nembhard, H. B. (2018). Healthcare market segmentation and data mining: A systematic review. Health Marketing Quarterly, 35, 186-208.

Vermeulen, E., Stronks, K., Visser, M., Brouwer, I. A., Schene, A. H., Mocking, R. J. T., . . Nicolaou, M. (2016). The association between dietary patterns derived by reduced rank regression and depressive symptoms over time: The Invecchiare in Chianti (InCHIANTI) study. British Journal of Nutrition, 115, 2145-2153.

Verplanken, B., \& Wood, W. (2006). Interventions to break and create consumer habits. Journal of Public Policy \& Marketing, 25, 90-103.

Videon, T. M., \& Manning, C. K. (2003). Influences on adolescent eating patterns: The importance of family meals. Journal of Adolescent Health, 32, 365-373.

Vidgen, H. A., \& Gallegos, D. (2014). Defining food literacy and its components. Appetite, 76, 50-59.

Viner, R. M., Ozer, E. M., Denny, S., Marmot, M., Resnick, M., Fatusi, A., \& Currie, C. (2012). Adolescence and the social determinants of health. The Lancet, 379, 1641-1652.

Wang, X., Yu, C., \& Wei, Y. (2012). Social media peer communication and impacts on purchase intentions: A consumer socialization framework. Journal of Interactive Marketing, 26, 198-208.

Whitaker, R. C., Wright, J. A., Pepe, M. S., Seidel, K. D., \& Dietz, W. H. (1997). Predicting obesity in young adulthood from childhood and parental obesity. The New England Journal of Medicine, 337, 869-873.

World Health Organization. (2014). Health for the world's adolescents: A second chance in the second decade: summary. No. WHO/FWC/MCA/14.05. Geneva, Switzerland: World Health Organization. Retrieved from https://apps.who.int/iris/handle/10665/112750

World Health Organization. (2015). Healthy diet (digital version). Retrieved from http://www.who.int/mediacen tre/factsheets/fs394/en/

Woodside, A., Nielson, R., Walters, R., \& Muller, G. (1998). Preference segmentation of health care services: The old-fashioneds, value conscious, affluents, and professional want-it-alls. Journal of Health Care Marketing, 8 , $14-24$.

Worsley, A. (2002). Nutrition knowledge and food consumption: Can nutrition knowledge change food behaviour? Asia Pacific Journal of Clinical Nutrition, 11, S579-S585.

Wymer, W. (2011). Developing more effective social marketing strategies. Journal of Social Marketing, 1, 17-31.

\section{Author Biographies}

Sabina De Rosis, PhD, currently works as a post-doc research fellow at the Institute of Management Department EMbeDS, Scuola Superiore Sant'Anna, in the Laboratorio Management e Sanità (MeS). Her research is focused on public participation into strategies, actions and services' design, delivery and assessment, with a focus on public healthcare.

Francesca Pennucci, MA, is a PhD candidate at the Institute of Management of the Scuola Superiore Sant'Anna, Pisa. Her research focuses both on conceptual frameworks, and on interventions and methodological tools, which can be helpful in studying how people's active role can have an impact on the value creation chain in the healthcare system.

Chiara Seghieri is associate professor of Social Statistics at the Laboratorio Management e Sanità (MeS) of Scuola Superiore Sant'Anna of Pisa (Italy). Her current research interests focus on the development of statistical methods for health services research, including reporting on quality of care using observational data. 